\title{
Paclitaxel-induced hypothermia and hypoperfusion increase breast cancer metastasis and angiogenesis in mice
}

\author{
NOZOMI AMI ${ }^{1,2}$, HIDEKI SATO ${ }^{1}$ and YOSHIHIRO HAYAKAWA ${ }^{2}$ \\ ${ }^{1}$ R\&D Center, Terumo Corp., Nakai-machi, Kanagawa 259-0151; ${ }^{2}$ Division of Pathogenic Biochemistry, \\ Institute of Natural Medicine, University of Toyama, Toyama-shi, Toyama 930-0194, Japan
}

Received June 23, 2017; Accepted November 6, 2017

DOI: $10.3892 / \mathrm{ol} .2017 .7621$

\begin{abstract}
Housing temperature has been shown to influence thermoregulation and behavior of preclinical cancer models; and anti-cancer drugs typically reduce peripheral blood flow and body temperature. In the present study, the effects of paclitaxel (PTX)-induced reduction of body temperature and peripheral blood flow on metastatic 4T1 breast cancer was investigated in a mouse model and the modification of these effects by thermoneutral temperature was also assessed. A single dose of PTX decreased the body temperature and peripheral blood flow in mice housed at a standard temperature $\left(23^{\circ} \mathrm{C}\right)$. Furthermore, although lung metastasis and angiogenesis of inoculated 4T1 cells increased in mice pretreated with PTX, mice housed at a thermoneutral temperature $\left(30^{\circ} \mathrm{C}\right)$ could compensate their body temperature and peripheral blood flow compared with control mice, and also suppressed 4T1 angiogenesis and metastasis to lung. The present results imply that maintenance of body temperature or efficient energy supply for thermogenesis may prevent tumor relapse or metastasis after chemotherapy.
\end{abstract}

\section{Introduction}

To maintain body temperature, both energy intake and blood circulation are critically important. Anti-cancer drugs are known to induce peripheral neuropathy through nerve hypoperfusion and reduction of vasa nervorum density (1). In a mouse study, paclitaxel (PTX) and oxaliplatin induced mechanical allodynia along with peripheral hypoperfusion (2). Although blood flow is essential for all cells in the body to obtain nutrients and oxygen (3), solid tumors often require a greater blood supply to support their rapid growth; therefore, angiogenesis is critical for tumor growth (4). In this regard, angiogenesis

Correspondence to: Professor Yoshihiro Hayakawa, Division of Pathogenic Biochemistry, Institute of Natural Medicine, University of Toyama, 2630 Sugitani, Toyama-shi, Toyama 930-0194, Japan E-mail: haya@imn.u-toyama.ac.jp

Key words: chemotherapy, body temperature, peripheral blood flow, angiogenesis, metastasis inhibitors target tumors based by hampering blood supply, leading to tumor growth arrest. In contrast, chronic reduction in blood flow and low oxygen availability may result in tumor hypoxia, which has been implicated in tumor propagation by adapting cells to nutrient deprivation, or by facilitating proliferation, local invasion, and metastatic spread through induction of angiogenesis, lymphangiogenesis, and/or acquisition of epithelial-to-mesenchymal phenotypes (5-8).

Chemotherapy reportedly reduces body temperature $(9,10)$ and hypothermia is known to suppress immunity by delaying and prolonging production of proinflammatory cytokines $(11,12)$. Considering the role of the immune system in tumor surveillance, such immune suppression by hypothermia may increase risk of tumor cell progression (13). Indeed, transplant patients treated with immunosuppressive drugs (14), patients with chronic inflammation and infection, and elderly persons (15) are well known to have increased susceptibility to malignancies. Interestingly, housing temperature reportedly influences results of preclinical cancer models (16). Endogenous immune responses were suppressed under standard housing temperature $\left(20-26^{\circ} \mathrm{C}\right)$ compared with thermoneutral temperature $\left(30-32^{\circ} \mathrm{C}\right)$ because the energy needed for intact immune function is consumed to maintain body temperature (16).

In this study, we investigated effects on metastatic breast cancer by PTX-induced reductions in body temperature and peripheral blood flow in a mouse model, and the influence of thermoneutral temperature on these effects.

\section{Materials and methods}

Animals. Female BALB/c mice (7 weeks old; CLEA Japan, Tokyo, Japan) were used. We used 6-7 animals in each study group, which were housed 6-7 mice per cage under controlled temperature and humidity $\left(23 \pm 2^{\circ} \mathrm{C}, 50 \pm 10 \%\right)$, on a 12-h light/dark cycle. Mice had access to tap water and food ad libitum. All experiments were approved and performed according to the guidelines of the Committee for Animal Experiments at Terumo Corporation and the Care and Use Committee of Laboratory Animals of the University of Toyama.

Reagents and cells. PTX (Taxol ${ }^{\circledR}$; Bristol-Myers Squibb, Tokyo, Japan), formulated at $6 \mathrm{mg} / \mathrm{ml}$, was dissolved in 
a vehicle of $13.3 \%$ absolute anhydrous ethanol (Wako Pure Chemical, Osaka, Japan), $13.3 \%$ Cremophore ${ }^{\circledR}$ EL (Sigma-Aldrich Japan, Tokyo, Japan) and $73.4 \%$ saline (Otsuka Pharmaceutical Factory, Tokushima, Japan). We obtained pGL4.50 [luc2P/CMV-RE/Hygro] vector and D-Luciferin from Promega (Sunnyvale, CA, USA). Mouse mammary carcinoma 4T1 cells that expressed the luciferase gene (4T1-Luc2 cells) were established and maintained as described before (17).

Measurement of body temperature and peripheral blood flow. Rectal temperature was measured three times for each animal, using a rectal probe (RET-3; Physitemp, Clifton, NJ, USA) and meter (BAT-12R; Physitemp), from which averaged values were obtained. Body temperatures were measured at approximately 9:00 a.m. Blood flow of ventral tail artery was recorded using laser Doppler blood flowmeter (ALF21R; ADMEDEC, Tokyo, Japan). Blood flow was measured three times for about $30 \mathrm{sec}$. Values for the 10-second interval between 10 and $20 \mathrm{sec}$ from the starting point were averaged. Peripheral blood flow was measured at about 10:00 a.m. Mice were injected with PTX (8 or $12 \mathrm{mg} / \mathrm{kg}$ ) intraperitoneally (i.p.) on day 1 . Body temperature was measured on day 1 before PTX injection, and once a day until day 10. Peripheral blood flow was measured on day 1 before PTX injection, and on days 3, 5, 7 and 10 . All measurements were conducted at $23^{\circ} \mathrm{C}$. Mice were divided into three groups according to their body temperatures on day 1 .

Thermoneutral housing. To keep animals at thermoneutral temperature, mice were housed at $30^{\circ} \mathrm{C}$ in a cooled incubator (MIR-154; Panasonic, Osaka, Japan) with 12-h light/dark cycle.

Experimental lung metastasis model. Six days after 4T1-Luc2 cell inoculation, mice were injected with D-luciferin $(150 \mathrm{mg} / \mathrm{kg})$ intraperitoneally. Twenty min later, these mice were sacrificed and their lungs were removed. Lung luminescence was measured with an imaging system (IVIS Spectrum; Caliper Life Science, Hopkinton, MA, USA) (17).

Matrigel plug angiogenesis assay. Seven days after injection of 4T1-Luc2 cells/Matrigel matrix, the mice were injected intravenously with $100 \mu \mathrm{l}$ of $1 \%$ Evans blue dye (Sigma-Aldrich Japan). After $30 \mathrm{~min}$, mice were cardiac-perfused with phosphate-buffered saline (Life Technologies Japan, Tokyo, Japan) containing $2 \mathrm{mM}$ EDTA (Nacalai Tesque, Kyoto, Japan) under 3\% isoflurane [isoflurane inhalation solution (Pfizer, Tokyo, Japan)] anesthesia. Matrigel plugs were removed and incubated with formamide (Wako Pure Chemical, Osaka, Japan) at $37^{\circ} \mathrm{C}$ for $48 \mathrm{~h}$ to elute the Evans blue dye. The amount of Evans blue dye was quantified by use of a spectrometer $(620 \mathrm{~nm})(18)$.

Statistical analysis. Data are expressed as mean \pm standard error of the mean (SEM). Data were analyzed with a two-way analysis of variance followed by post hoc analysis with the Bonferroni's test. In the metastatic and angiogenesis assay, data were analyzed with one-way analysis of variance followed by post hoc analysis with Tukey's test. Statistical analysis was performed using Prism (version 6.07; GraphPad Software, Inc., La Jolla, CA, USA) (19).
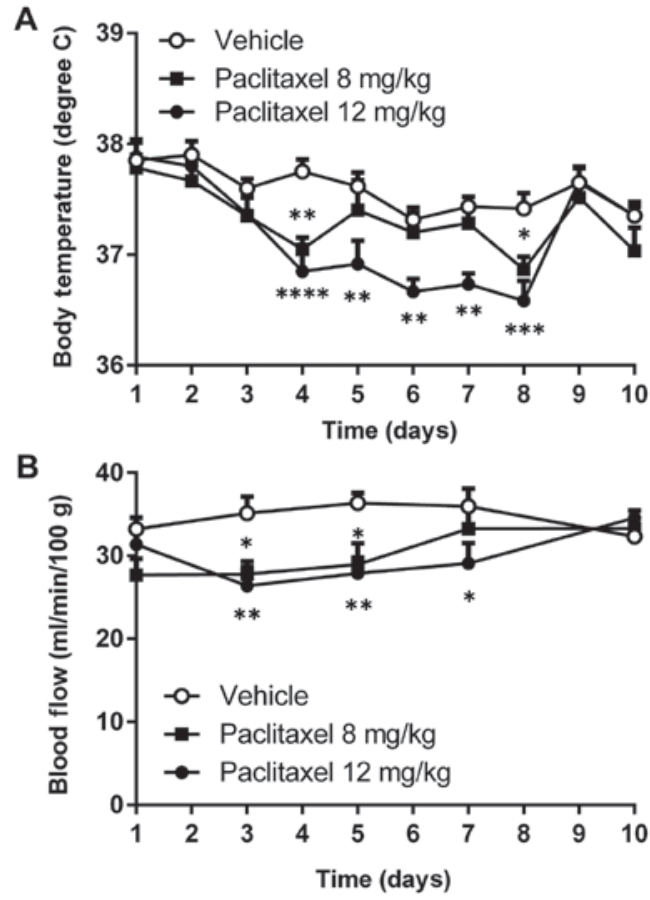

Figure 1. Effect of paclitaxel on body temperature and peripheral blood flow at standard housing temperature $\left(23^{\circ} \mathrm{C}\right)$. Mice were treated with paclitaxel ( 8 or $12 \mathrm{mg} / \mathrm{kg}$, i.p.) on day 1 ; (A) body temperature and (B) ventral artery blood flow were measured at the indicated days after treatment. Data are expressed as mean \pm SEM $(n=6)$. ${ }^{*} \mathrm{P}<0.05,{ }^{* *} \mathrm{P}<0.01,{ }^{* * *} \mathrm{P}<0,001,{ }^{* * * * *} \mathrm{P}<0.0001$, compared with vehicle-treated group (Bonferroni's post test).

\section{Results}

Effect of PTX on body temperature and peripheral blood flow. Significant reduction in body temperature was observed after a single injection of PTX $(12 \mathrm{mg} / \mathrm{kg})$ into Balb/c mice during days $4-8$ at $23^{\circ} \mathrm{C}$ (Fig. 1A). Peripheral blood flow was also reduced by about $25 \%$ compared with untreated mice during days 3-7 after a single injection of PTX (12 mg/kg; Fig. 1B).

Thermoneutral temperature reversed body temperature reduction and decreased blood flow induced by PTX. To find whether thermoneutral temperature could compensate for reduced body temperature and peripheral blood flow induced by PTX, mice were housed at either $23^{\circ} \mathrm{C}$ or $30^{\circ} \mathrm{C}$ after being injected with PTX. Although PTX treatment reduced both body temperature and peripheral blood flow of mice housed at $23^{\circ} \mathrm{C}$ (Fig. 2A and B), PTX-treated mice housed at $30^{\circ} \mathrm{C}$ showed no reductions in either body temperature or peripheral blood flow (Fig. 2C and D). These data indicate that thermoneutral temperature can compensate for PTX-induced reductions of body temperature and peripheral blood flow.

Thermoneutral temperature reverses $P T X^{\prime} s$ metastasis-promoting effect. We next examined whether body temperature reduction caused by PTX treatment enhanced in vivo malignant behaviors such as metastasis or angiogenesis, using murine metastatic mammary cancer cell line 4T1. Mice were treated with PTX and housed at either $23^{\circ} \mathrm{C}$ or $30^{\circ} \mathrm{C}$ for the next 4 days, and then intravenously injected with 4T1-Luc2 cells. Upon 4T1-Luc2 cell inoculation, all mice were housed at 

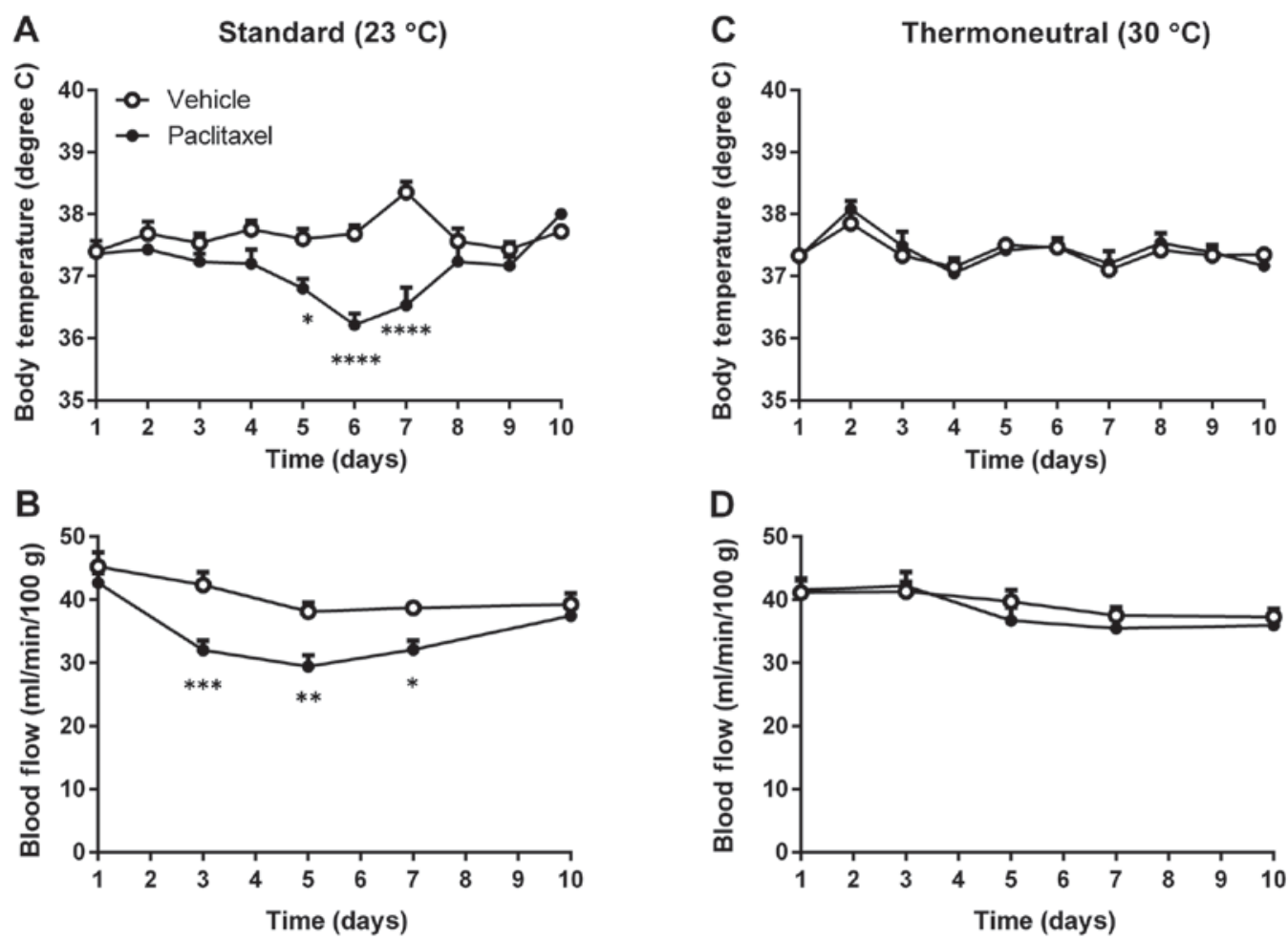

Figure 2. Effect of thermoneutral housing on paclitaxel-induced reduction of body temperature and peripheral blood flow. Mice were treated with paclitaxel $(12 \mathrm{mg} / \mathrm{kg})$ on day 1 . Body temperature (A and C) and ventral artery blood flow (B and D) were measured at the indicated days after treatment. Groups of mice were housed at either standard $\left(\mathrm{A}\right.$ and $\mathrm{B}$; at $\left.23^{\circ} \mathrm{C}\right)$ or thermoneutral $\left(\mathrm{C}\right.$ and $\mathrm{D}$; at $\left.30^{\circ} \mathrm{C}\right)$ temperature after paclitaxel treatment. Data are expressed as mean $\pm \operatorname{SEM}(n=6) .{ }^{*} \mathrm{P}<0.05,{ }^{* *} \mathrm{P}<0.01,{ }^{* * * *} \mathrm{P}<0,001,{ }^{* * * * *} \mathrm{P}<0.0001$, compared with vehicle-treated group (Bonferroni's post test).

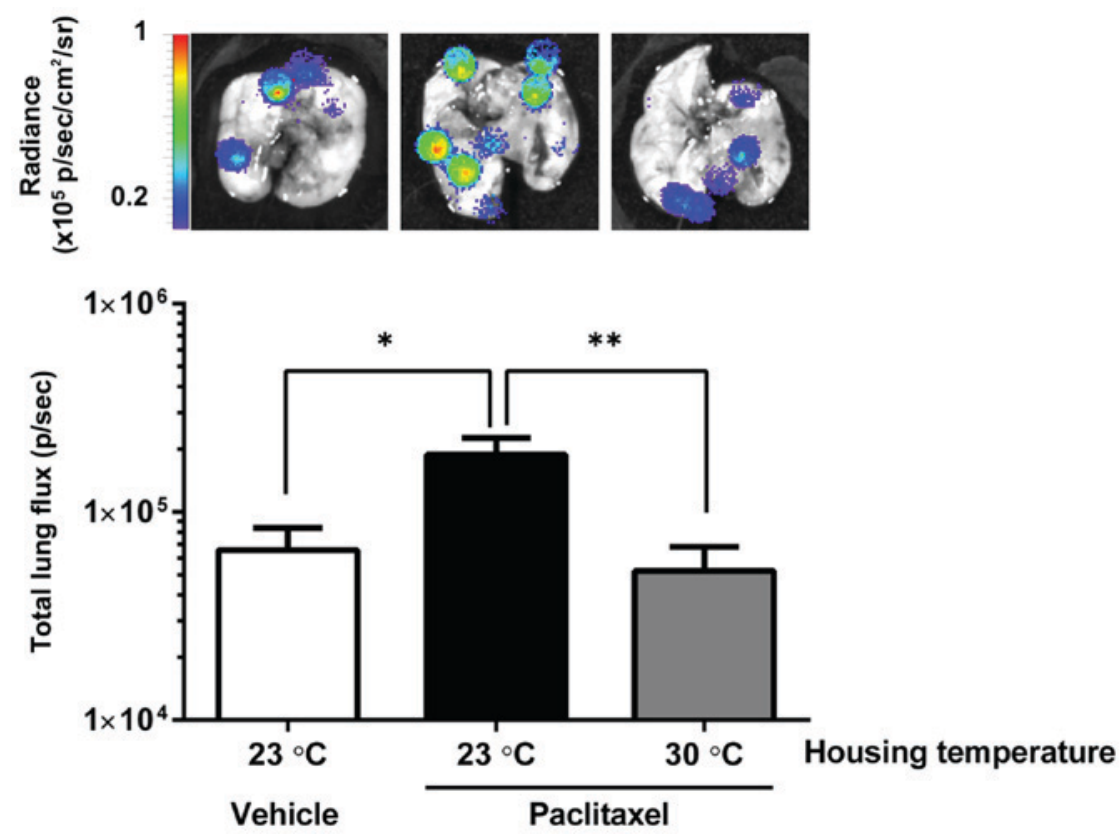

Figure 3. Effect of thermoneutral housing on pro-metastatic effect of paclitaxel. Mice were treated with paclitaxel $(12 \mathrm{mg} / \mathrm{kg})$, housed at either $23^{\circ} \mathrm{C}$ or $30^{\circ} \mathrm{C}$ for the next 4 days, and then given an intravenous injection of 5x105 4T1-Luc2 cells. Six days after tumor inoculation, mice were sacrificed and lung metastases were measured by the IVIS system. Open column, vehicle-treated mice at $23^{\circ} \mathrm{C}$; black column, paclitaxel-treated mice $(12 \mathrm{mg} / \mathrm{kg})$ at $23^{\circ} \mathrm{C}$; gray column, paclitaxel-treated mice $(12 \mathrm{mg} / \mathrm{kg})$ at $30^{\circ} \mathrm{C}$. Data are expressed as mean $\pm \operatorname{SEM}(n=7) .{ }^{*} \mathrm{P}<0.05,{ }^{* * *} \mathrm{P}<0.01$, compared usingTukey's post test.

$23^{\circ} \mathrm{C}$. As shown in Fig. 3, pre-treatment with PTX significantly increased metastatic lung colonization by $4 \mathrm{~T} 1-\mathrm{Luc} 2$ cells among mice housed at $23^{\circ} \mathrm{C}$. In contrast, the mice housed at $30^{\circ} \mathrm{C}$ did not show such enhanced metastatic colonization (Fig. 3).
To evaluate angiogenesis, we used a Matrigel plug assay with 4T1-Luc2 cells under the same treatment and housing conditions as the metastasis assay. We observed induction of more angiogenesis in the PTX-treated group compared with the 
vehicle-treated group, although the difference was not statistically significant $(\mathrm{P}=0.0557)$. The mice housed at $30^{\circ} \mathrm{C}$ showed less angiogenesis in the 4T1-Luc2/Matrigel plug compared with mice housed at $23^{\circ} \mathrm{C}$ (Fig. 4). These results indicate the potential advantage of thermoneutral housing temperature to prevent the metastasis- and angiogenesis-promoting effects of PTX.

\section{Discussion}

Mammalian body temperature is generally regulated by a balance between heat loss and generation $(20,21)$. Several body reactions defend against cold, such as thermoregulatory behaviors to reduce the loss of heat generated during basal metabolism, cutaneous vasoconstriction to conserve heat in the body core, and heat production, including activation of brown adipose tissue (BAT), and shivering behavior in skeletal muscle (21-23). In this study, we observed reduced peripheral blood flow followed by reduced body temperature after single injections of PTX. These reductions were lasted about 8 days, then recovered. Compared with the vehicle-treated group, significant blood flow reduction was observed in the low-dose PTX-treated group, although body temperature was comparable between the two groups over the same time period (days 5-7). Therefore, we presume that PTX reduces peripheral blood flow as a compensatory mechanism for reduction of body temperature. Importantly, supplying exogenous heat by housing the PTX-treated mice at $30^{\circ} \mathrm{C}$ compensated reductions in both body temperature and peripheral blood flow. These results suggest that impaired heat generation is a mechanism of PTX-induced body-temperature reduction. Considering that BAT activity is known to decrease after treatment with taxanes in breast cancer patients (24), PTX-induced reduction of body temperature might involve inhibiting BAT activity. BAT activity is reported to be involved in psychological stress-induced hyperthermia (25). We observed a slight elevation of body temperature on day 7 in Fig. 2A. We don't know the exact reason which caused the elevation of body temperature. However, the degree of rise in body temperature of control group was greater than that of PTX-treated group, which might be because of the inhibiting BAT activity by PTX. In any case, the exact mechanism through which PTX treatment reduces body temperature remains to be elucidated.

Thermoneutral temperature refers to the temperature at which the energy expenditure required to maintain body temperature is lowest; for mice, this is usually $30-32^{\circ} \mathrm{C}(16,26,27)$. By housing mice at thermoneutral temperature, the malignancy-promoting effects of PTX were suppressed as body temperature and peripheral blood flow were compensated. Notably, we excluded the possibility that the reduced lung metastasis by 4T1 cells was a direct anti-cancer effect of PTX because the 4T1 inoculations in our study were timed at 4 days after the PTX injections, so that the administered PTX should have been mostly cleared by then (28). Importantly, tumor formation, growth, and metastasis of cancer cells are reportedly reduced by keeping mice at thermoneutral temperature through modulating immune responses (27). Body temperature fell by $1-2^{\circ} \mathrm{C}$ with tumor growth, which exhausted the mice's ability to maintain normal body temperature at standard housing condition (27), whereas

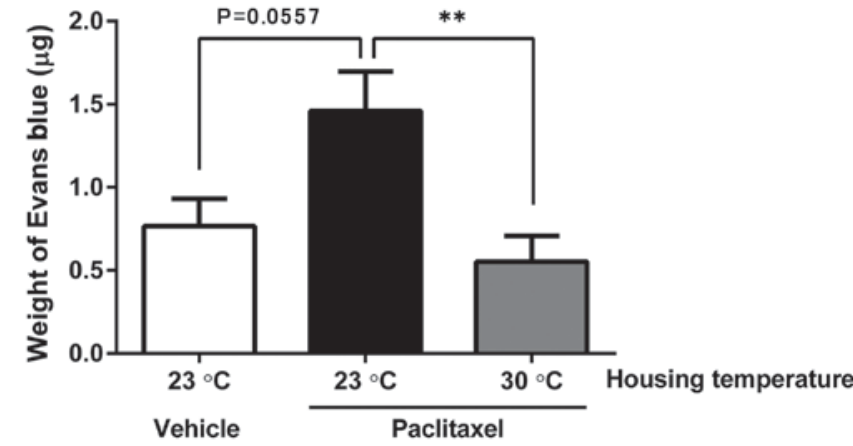

Figure 4. Effect of thermoneutral housing on paclitaxel's pro-angiogenic effect. Mice were treated with paclitaxel $(12 \mathrm{mg} / \mathrm{kg})$ and housed at either $23^{\circ} \mathrm{C}$ or $30^{\circ} \mathrm{C}$ for the next 4 days. They were then each given a subcutaneous injection of $5 \times 10^{4} 4 \mathrm{~T} 1-\mathrm{Luc} 2$ cells with Matrigel matrix. Seven days after the 4T1-Luc2 cells/Matrigel matrix inoculation, mice were injected with Evans blue dye, to quantify the extent of angiogenesis. Open column, vehicle-treated mice at $23^{\circ} \mathrm{C}$; black column, paclitaxel-treated mice $(12 \mathrm{mg} / \mathrm{kg})$ at $23^{\circ} \mathrm{C}$; gray column, paclitaxel-treated mice $(12 \mathrm{mg} / \mathrm{kg})$ at $30^{\circ} \mathrm{C}$. Data are expressed as mean $\pm \operatorname{SEM}(n=6-7) .{ }^{* *} \mathrm{P}<0.01$, compared using Tukey's post test.

thermoneutral housing supplied sufficient heat to allow them to conserve energy needed to maintain an intact immune system. Indeed, anesthesia-induced hypothermia $\left(30-32^{\circ} \mathrm{C}\right)$ is known to increase lung metastasis from mammary adenocarcinoma cells by suppressing natural killer cell activity (29). In obese mice, body temperature is reportedly $1-2^{\circ} \mathrm{C}$ lower than in control mice $(30,31)$; treatment with leptin (an important regulator of energy balance) suppresses lung metastasis (32) and increases body temperature (33). Taken together, these studies suggest that reduced body temperature suppresses immune-system cancer surveillance, and facilitates tumor progression. Thus thermoneutral temperature may compensate such immune suppression.

To achieve distant metastasis, cancer cells must enter the circulation and be exposed to the fluid shear stress in the blood stream, which is influenced by such factors as fluid rate and viscosity (34). Although increased fluid shear force can support cancer cells migrating and binding to the vascular endothelium (35), it also affects tumor cell survival. As we saw, PTX promotes increased metastatic lung colonization by 4T1-Luc 2 cells along with reduced peripheral blood flow. Reduced fluid shear force might be a mechanism that affects lung metastasis in PTX-treated mice.

Hypoxia can also influence tumor cells, as a stressor that impairs growth or as a trigger for malignant processes, including angiogenesis. Angiogenesis has a critical function in tumor metastasis because its permeable and heterogeneous vasculature facilitates extravasation, circulation, and relocation of tumor cells $(3,4,6)$. Thus, hypoxia caused by PTX-induced peripheral blood flow reduction might be a complicating factor in metastasis.

In this study, we investigated the influence of reduction of body temperature and peripheral blood flow by PTX on metastasis and angiogenesis. Further studies will be necessary to clarify the mechanism how PTX reduces body temperature or the mechanism how reduced body temperature affects the other systems such as the immune-system.

In summary, we propose that dysregulation of body temperature and peripheral blood flow by PTX treatment 
might decrease fluid shear force, increase tumor hypoxia, and/or suppress immunity, thus promoting metastasis or angiogenesis. Maintenance of body temperature or energy supply for thermogenesis may help prevent tumor relapse or metastasis after chemotherapy.

\section{Acknowledgements}

The authors thank Keisuke Ogura for his technical support.

\section{References}

1. Kirchmair R, Tietz AB, Panagiotou E, Walter DH, Silver M, Yoon YS, Schratzberger P, Weber A, Kusano K, Weinberg DH, et al: Therapeutic angiogenesis inhibits or rescues chemotherapy-induced peripheral neuropathy: Taxol- and thalidomide-induced injury of vasa nervorum is ameliorated by VEGF. Mol Ther 15: 69-75, 2007.

2. Gauchan P, Andoh T, Kato A, Sasaki A and Kuraishi Y: Effects of the prostaglandin E1 analog limaprost on mechanical allodynia caused by chemotherapeutic agents in mice. J Pharmacol Sci 109: 469-472, 2009.

3. Paduch R: The role of lymphangiogenesis and angiogenesis in tumor metastasis. Cell Oncol (Dordr) 39: 397-410, 2016.

4. Gupta MK and Qin RY: Mechanism and its regulation of tumor-induced angiogenesis. World J Gastroenterol 9: 1144-1155, 2003.

5. Vaupel P and Harrison L: Tumor hypoxia: Causative factors, compensatory mechanisms, and cellular response. Oncologist 9 (Suppl 5): S4-S9, 2004.

6. Muz B, de la Puente P, Azab F and Azab AK: The role of hypoxia in cancer progression, angiogenesis, metastasis, and resistance to therapy. Hypoxia (Auckl) 3: 83-92, 2015.

7. Morfoisse F, Renaud E, Hantelys F, Prats AC and Garmy-Susini B: Role of hypoxia and vascular endothelial growth factors in lymphangiogenesis. Mol Cell Oncol 2: e1024821, 2015.

8. Cao Z, Shang B, Zhang G, Miele L, Sarkar FH, Wang Z and Zhou Q: Tumor cell-mediated neovascularization and lymphangiogenesis contrive tumor progression and cancer metastasis. Biochim Biophys Acta 1836: 273-286, 2013.

9. Guindon J and Hohmann AG: Use of sodium bicarbonate to promote weight gain, maintain body temperature, normalize renal functions and minimize mortality in rodents receiving the chemotherapeutic agent cisplatin. Neurosci Lett 544: 41-46, 2013.

10. Guindon J, Deng L, Fan B, Wager-Miller J and Hohmann AG: Optimization of a cisplatin model of chemotherapy-induced peripheral neuropathy in mice: Use of vitamin $\mathrm{C}$ and sodium bicarbonate pretreatments to reduce nephrotoxicity and improve animal health status. Mol Pain 10: 56, 2014.

11. Fairchild KD, Viscardi RM, Hester L, Singh IS and Hasday JD: Effects of hypothermia and hyperthermia on cytokine production by cultured human mononuclear phagocytes from adults and newborns. J Interf cytokine Res 20: 1049-1055, 2000.

12. Sahdo B, Evans AL, Arnemo JM, Fröbert O, Särndahl E and Blanc S: Body temperature during hibernation is highly correlated with a decrease in circulating innate immune cells in the brown bear (Ursus arctos): A common feature among hibernators? Int J Med Sci 10: 508-514, 2013.

13. Ribatti D: The concept of immune surveillance against tumors. The first theories. Oncotarget 8: 7175-7180, 2017.

14. Peto J: Cancer epidemiology in the last century and the next decade. Nature 411: 390-395, 2001.

15. Melvold RW and Sticca RP: Basic and tumor immunology: A review. Surg Oncol Clin N Am 16: 711-735, vii, 2007.

16. Hylander BL and Repasky EA: Thermoneutrality, mice, and cancer: A heated opinion. Trends Cancer 2: 166-175, 2016.

17. Lou C, Takahashi K, Irimura T, Saiki I and Hayakawa Y: Identification of Hirsutine as an anti-metastatic phytochemical by targeting NF- $\kappa$ B activation. Int J Oncol 45: 2085-2091, 2014.
18. Suehiro J, Hamakubo T, Kodama T, Aird WC and Minami T: Vascular endothelial growth factor activation of endothelial cells is mediated by early growth response-3. Blood 115: 2520-2532, 2010.

19. Lin WL, Wu SK, Chiang CF, Hsu YH, Lin TH, Liou HC, Fu WM and Lin WL: Short-time focused ultrasound hyperthermia enhances liposomal doxorubicin delivery and antitumor efficacy for brain metastasis of breast cancer. Int J Nanomedicine 9: 4485-4494, 2014

20. Alawi KM, Aubdool AA, Liang L, Wilde E, Vepa A, Psefteli MP, Brain SD and Keeble JE: The sympathetic nervous system is controlled by transient receptor potential vanilloid 1 in the regulation of body temperature. FASEB J 29: 4285-4298, 2015.

21. Feketa VV and Marrelli SP: Induction of therapeutic hypothermia by pharmacological modulation of temperature-sensitive TRP channels: Theoretical framework and practical considerations. Temperature (Austin) 2: 244-257, 2015.

22. Morrison SF: Central control of body temperature. F1000Res 5: pii: F1000, 2016.

23. Ootsuka Y and Tanaka M: Control of cutaneous blood flow by central nervous system. Temperature (Austin) 2: 392-405, 2015.

24. Gadea E, Thivat E, Merlin C, Paulon R, Kwiatkowski F, Chadeyras JB, Coudert B, Boirie Y, Morio B and Durando X: Brown adipose tissue activity in relation to weight gain during chemotherapy in breast cancer patients: A pilot study. Nutr Cancer 66: 1092-1096, 2014.

25. Kataoka N, Hioki H, Kaneko T and Nakamura K: Psychological stress activates a dorsomedial hypothalamus-medullary raphe circuit driving brown adipose tissue thermogenesis and hyperthermia. Cell Metab 20: 346-358, 2014.

26. Lodhi IJ and Semenkovich CF: Why we should put clothes on mice. Cell Metab 9: 111-112, 2009.

27. Kokolus KM, Capitano ML, Lee CT, Eng JW, Waight JD, Hylander BL, Sexton S, Hong CC, Gordon CJ, Abrams SI and Repasky EA: Baseline tumor growth and immune control in laboratory mice are significantly influenced by subthermoneutral housing temperature. Proc Natl Acad Sci USA 110: 20176-20181, 2013.

28. Ma YL, Ye J, Zhang PX, Xia XJ and Liu YL: Comparative study on pharmacokinetics and tissue distribution of a novel microemulsion based on the paclitaxel/L-OH lipid complex and paclitaxel injection in cremophor. Yao Xue Xue Bao 48: 1698-1704, 2013 (In Chinese).

29. Ben-Eliyahu S, Shakhar G, Rosenne E, Levinson Y and Beilin B: Hypothermia in barbiturate-anesthetized rats suppresses natural killer cell activity and compromises resistance to tumor metastasis: A role for adrenergic mechanisms. Anesthesiology 91: 732-740, 1999.

30. Jürgens HS, Schürmann A, Kluge R, Ortmann S, Klaus S, Joost HG and Tschöp MH: Hyperphagia, lower body temperature, and reduced running wheel activity precede development of morbid obesity in New Zealand obese mice. Physiol Genomics 25: 234-241, 2006.

31. Klaus S, Münzberg H, Trüloff C and Heldmaier G: Physiology of transgenic mice with brown fat ablation: Obesity is due to lowered body temperature. Am J Physiol 274: R287-R293, 1998.

32. Mori A, Sakurai H, Choo MK, Obi R, Koizumi K, Yoshida C, Shimada Y and Saiki I: Severe pulmonary metastasis in obese and diabetic mice. Int J Cancer 119: 2760-2767, 2006.

33. Luheshi GN, Gardner JD, Rushforth DA, Loudon AS and Rothwell NJ: Leptin actions on food intake and body temperature are mediated by IL-1. Proc Natl Acad Sci USA 96: 7047-7052, 1999.

34. Kon K, Maeda N and Shiga T: Erythrocyte deformation in shear flow: Influences of internal viscosity, membrane stiffness, and hematocrit. Blood 69: 727-734, 1987.

35. Mitchell MJ and King MR: Fluid shear stress sensitizes cancer cells to receptor-mediated apoptosis via trimeric death receptors. New J Phys 15: 15008, 2013.

This work is licensed under a Creative Commons Attribution-NonCommercial-NoDerivatives 4.0 International (CC BY-NC-ND 4.0) License. 